See discussions, stats, and author profiles for this publication at: https://www.researchgate.net/publication/341191431

\title{
Monolingual and bilingual children's processing of coarticulation cues during spoken word recognition
}

Article in Journal of Child Language · May 2020

DOI: $10.1017 / 50305000920000100$

CITATIONS

READS

4

77

3 authors, including:

Tania S Zamuner

University of Ottawa

48 PUBLICATIONS 607 CITATIONS

SEE PROFILE 
Desmeules-Trudel, F., Moore, C. \& Zamuner, T.S. (2020). Monolingual and bilingual children's processing of coarticulation cues during spoken word recognition. Journal of Child Language, 47, 1189-1206.

\section{Monolingual and bilingual children's processing of coarticulation cues during spoken word recognition}

Félix Desmeules-Trudel ${ }^{\mathrm{a} 1}$ (fdesmeul@uwo.ca), Charlotte Moore ${ }^{\mathrm{b}}$ (charlotte.moore@duke.edu) and Tania S. Zamuner ${ }^{\text {a }}$ tania.zamuner@uottawa.ca)

${ }^{a}$ Department of Linguistics, University of Ottawa

${ }^{\mathrm{b}}$ Department of Psychology, Duke University

\section{Address of correspondence:}

Félix Desmeules-Trudel

Western Interdisciplinary Research Building 5182

University of Western Ontario

London, ON

N6A 3K7

Canada

Phone: +1(519)661-3529

Email: fdesmeul@uwo.ca

Acknowledgements: We thank Sarah Colby, Maya Pilin, Myriam Ducos, Émilie Piché and Keara Boyce for assistance with data collection. FDT benefited from doctoral scholarships from the Fonds de Recherche du Québec - Société et Culture and Social Sciences and Humanities Research Council of Canada (SSHRC), CM from a M.A. scholarship from SSHRC, and TZ from a Natural Sciences and Engineering Research Council of Canada research grant for the completion of this research. We also thank audiences at the ICIS 2018 and the CLA 2017 annual meeting.

Keywords: Coarticulation processing, language development, bilingualism, eye tracking

${ }^{1}$ Corresponding author.

Current affiliation: Department of Psychology (Brain and Mind Institute), University of Western Ontario 


\begin{abstract}
Bilingual children cope with a significant amount of phonetic variability when processing speech, and must learn to weigh phonetic cues differently depending on the cues' respective roles in their two languages. For example, vowel nasalization is coarticulatory and contrastive in French, but coarticulatory-only in English. In this study, we extended an investigation of the processing of coarticulation in two- to three-year-old English monolingual children (Zamuner, Moore \& Desmeules-Trudel, 2016) to a group of four- to six-year-old English monolingual children and age-matched English-French bilingual children. Using eye tracking, we found that older monolingual children and age-matched bilingual children showed more sensitivity to coarticulation cues than the younger children. Moreover, when comparing the older monolinguals and bilinguals, we found no statistical differences between the two groups. These results offer support for the specification of coarticulation in word representations, and indicate that in some cases, bilingual children possess language processing skills similar to monolinguals.
\end{abstract}

Keywords: Coarticulation processing, language development, bilingualism, eye tracking 


\section{Monolingual and bilingual children's processing of coarticulation cues during spoken word recognition}

\section{Introduction}

Processing spoken language is a complex task, in part due to the multi-dimensional and variable characteristics of speech. This ability continues to develop throughout childhood, even into adolescence (Rigler, Farris-Trimble, Greiner, Walker, Tomblin, \& McMurray, 2015). Language complexity is further intensified in multilingual contexts: learners who are exposed to more than one language also receive more variable speech input (Byers-Heinlein \& Fennell, 2014), and the multiplicity of phonetic cues from different languages can create challenges for the learner. The way that bilingual learners cope with variability is not well documented, especially in the context of spoken word recognition. Coarticulation, a process where sounds in words influence each other (Fowler, 1980), is an ever-present source of phonetic variability. Here, we investigate how children use fine-grained phonetic information (i.e. coarticulation) during word processing. First, we examine potential developmental changes between younger and older monolingual children. Second, we compare how older monolingual and bilingual children process coarticulation cues within words to examine the influence of bilingualism on language processing.

\section{Coarticulation processing in adults and children}

Coarticulation and phonetic variability impact spoken word recognition in adults (Archibald \& Joanisse, 2011; Beddor, McGowan, Boland, Coetzee, \& Basher, 2013; Dahan, Magnuson, Tanenhaus, \& Hogan, 2001; Desmeules-Trudel \& Zamuner, 2019; Gow, 2003; 
McMurray, Clayards, Tanenhaus, \& Aslin, 2008; McMurray, Tanenhaus, \& Aslin, 2002;

Salverda, Kleinschmidt, \& Tanenhaus, 2014) and children (Cross \& Joanisse, 2018; Johnson \& Jusczyk, 2001; Mahr, McMillan, Saffran, Weismer, \& Edwards, 2015; Paquette-Smith, Fecher, \& Johnson, 2016; Zamuner, Moore, \& Desmeules-Trudel, 2016). One coarticulatory phenomenon that influences auditory word recognition in monolingual English-speaking adults and young children is vowel nasalization (Beddor et al., 2013; Zamuner et al., 2016). Regressive vowel nasalization is a well-known coarticulatory pattern in English: vowels are partially nasalized before nasal consonants (Beddor, 2009; Cohn, 1990). The gesture associated with the nasal consonant (i.e. lowering of the velum) starts early and overlaps with the preceding vowel. This results in a vowel that has a different acoustic quality than when it is followed by a nonnasal consonant, likely due to a general loss in spectral energy (Delattre, 1965; Maeda, 1993) and the emergence of nasal formants and antiformants (Fujimura, 1962; Kurowski \& Blumstein, 1993). In perception, Beddor et al. (2013) found that English adult listeners recognize words with nasal consonants (e.g. scent) more quickly when the vowel was nasalized for a longer proportion of its duration than when it was nasalized for a shorter period. This indicates that coarticulation cues that occur early in the speech signal contributed to faster recognition of the target than coarticulation cues that occur late in the signal, even though nasalization cues are noncontrastive, optional, and variable in English. This finding demonstrates that listeners use coarticulatory vowel nasalization as a cue to word recognition. This evidence also suggests that word representations are rich and include some amount of fine-grained phonetic detail (see also Browman \& Goldstein, 1986; Pierrehumbert, 2002) which are traditionally considered redundant in the literature on lexical and phonological storage (Archangeli, 1988; Keating, 1988; Lahiri \& Marslen-Wilson, 1991; Steriade, 1995). 
Only a few studies have investigated the influence of coarticulation on word processing in development. Mahr et al. (2015) demonstrated the influence of coarticulation across word boundaries in 18-24-month-olds. In another study, Paquette-Smith et al. (2016) showed that twoyear-old toddlers (2;0 to $2 ; 5$ years old) were able to detect mismatches in a variety of coarticulation cues within words, suggesting that children can use subphonemic (i.e. fine-grained phonetic detail) information during spoken word recognition. This finding is further supported by Zamuner et al. (2016), who found that two- and three-year-old (monolingual) toddlers, as well as adults, use regressive vowel nasalization during on-line spoken word recognition. In the procedure, participants were presented with spoken words that had been cross-spliced to manipulate coarticulation cues. For example, the oral vowel from the word boat [bout] was replaced with the nasalized vowel from the word bone [bõ̃n] (the tilde represents nasalization

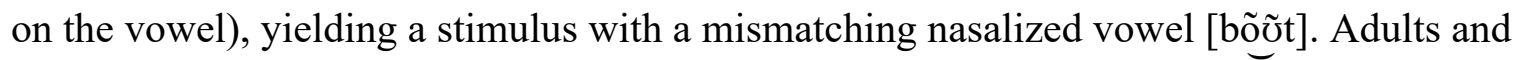
children were able to perceive the mismatching vowel nasalization, as indicated by the fact that they looked towards the image of the bone when they heard boat presented with a nasalized vowel. However, while adults ended up fixating the target boat well above chance by the end of the mismatching ([bõ $\left.\left.\tilde{\tau}^{t}\right]\right)$ trials, young children were unable to resolve the ambiguity caused by the cross-splicing. Instead, children hovered around chance towards the end of the trial, as if they could not decide which of the two words they had heard. This pattern of results showed timedependent sensitivity to coarticulation cues in toddlers, but also suggested that young listeners had difficulty resolving phonetic mismatches, which could be attributed to children's relative inefficiency in resolving lexical competition compared to adults (Huang \& Snedeker, 2011; Rigler et al., 2015; Sekerina \& Brooks, 2007; Swingley, Pinto, \& Fernald, 1999). As a tentative explanation based on Huang and Snedeker (2011) who found that five-year-old children showed 
continued interference from a competitor word, Zamuner et al. (2016) hypothesized that the smaller number of exemplars in memory may yield less robust word representations, and therefore result in lower activation of the target word when the auditory stimuli contained mismatches. Another complementary hypothesis was based on the less mature processing system in toddlers, yielding different competitor inhibition mechanisms (Huang \& Snedeker, 2011) and thus difficulties in recognizing ambiguous stimuli. This is an open question, as little work has examined the development of the link between spoken word processing and competitor inhibition in children (e.g. with nine-year-olds and sixteen-year-olds, see Rigler et al., 2015). However, the general finding seems to be that children are slower than adults at activating targets and inhibiting competitors (Cross \& Joanisse, 2018; Huang \& Snedeker, 2011; Rigler et al., 2015). In our study, we compare and extend the findings with toddlers from Zamuner et al. (2016) with a group of older monolingual children ( $4 ; 3$ to $6 ; 5$ years old), to investigate whether older children are better able to resolve mismatching coarticulatory cues.

\section{Second language perception and phonetic variability}

In addition to competition and inhibition mechanisms, exposure to phonetic variability has been shown to significantly impact lexical processing and word learning in children (e.g. Rost \& McMurray, 2009) as well as adult second language (L2) processing (Barcroft \& Sommers, 2005). However, the picture is not as clear for bilingual children. In their review article, Byers-Heinlein and Fennell (2014) argue that exposure to more than one language often results in more phonetic variation in the input for young learners, which could in turn result in maintained sensitivity to more phonetic contrasts than monolinguals. For example, bilinguals can be exposed to two languages from the same person or within code-switched sentences (Byers- 
Heinlein, 2013), and speech sounds produced by bilinguals are often different from monolinguals (MacLeod \& Stoel-Gammon, 2009). Bilingual learners are thus exposed to greater variability than monolinguals in general. Therefore, given that exposure to variability influences early lexical processing (Rost \& McMurray, 2009), bilingual learners are expected to maintain sensitivity to phonetic distinctions in both of their languages (for a review of the process in adults see Flege, 2007), i.e. they ought to discriminate more contrasts than monolinguals (Burns, Yoshida, Hill, \& Werker, 2007; Kuhl et al., 2008; Sundara, Polka \& Genesee, 2006). However, monolingual children are expected to maintain sensitivity to distinctions that are contrastive in their native language but lose this ability for foreign contrasts, as has been repeatedly shown in the literature (Kuhl et al., 2008).

To date, very little work has been conducted on the interplay between phonetic details and word recognition in bilingual children, a process that depends on the ability to distinguish sounds. Some work has examined how monolinguals and bilinguals process a Catalan vowel contrast between $/ \varepsilon /$ and /e/, which maps to a single vowel category in Spanish. Children's sensitivity to this contrast appears to depend partly on the stimuli used. In one study which included cognates (Ramon-Casas, Swingley, Sebastián-Gallés, \& Bosch, 2009), Catalan-Spanish bilingual children (aged 17 to 27 months) were insensitive to the /ع/-/e/ contrast. However, in a study using novel words (Ramon-Casas, Fennell, \& Bosch, 2017), bilinguals aged 21 and 22 months were able to perceive the /e/-/e/ contrast. While the work by Ramon-Casas and colleagues illustrate the variation in phonemic perception between monolinguals and bilinguals, these studies do not examine how bilingual children cope with coarticulatory information within spoken words. It is important to make this distinction because phonetic cues differ across languages in how they are realized (Cohn, 1990). For example, as mentioned above, vowel 
nasalization is coarticulatory, non-contrastive and variable in English (Beddor, 2009); vowel nasalization is not necessary for recognizing words in English, e.g. the word scent can be realized with a vowel that is more or less nasalized and listeners will recognize the word anyway. However, languages like French have phonological nasalization on vowels (Cohn, 1990), which can be variably realized as well, where words differ based solely on vowel nasalization (e.g. pain

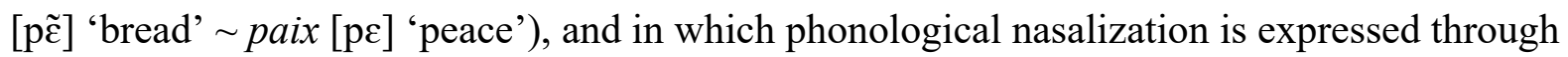
longer nasalization duration on the vowel (Desmeules-Trudel \& Brunelle, 2018). French learners must remain phonologically sensitive to vowel nasalization duration to differentiate between words, while the same cue does not indicate meaning differences between words for English listeners (i.e. variable nasalization duration always corresponds to a coarticulatorily nasalized vowel in English) even though the cue can be used to speed up word recognition.

When it comes to bilingual children's perception of phonetic properties that are present in both of their languages (e.g. vowel nasalization for English-French bilinguals, however with a different status), little is known concerning the perception of sublexical (e.g. coarticulatory) information. However, we know that young monolingual children's word recognition patterns are significantly influenced by coarticulation (Paquette-Smith et al., 2016; Zamuner et al., 2016) and bilingual children can maintain sensitivity to phonetic properties in more than one language (Burns et al., 2007; Kuhl et al., 2008; Ramon-Casas et al., 2017; Sundara et al., 2006).

This thus leads us to the first formal goal of the current study, which is to investigate if bilingual children are more or less sensitive to (mismatching) coarticulatory cues than monolinguals. Specifically, we aim to determine if the presence of contrastive vowel nasalization in the L2 (French) has an influence on the perception of nasal coarticulation (i.e. non-contrastive) in the L1 (English). In the current study, we operationalize sensitivity to nasal coarticulation 
through potential disruptions in the word recognition patterns of items that contain phonetic mismatches (i.e., the presence of a nasalized vowel in an oral-consonant context, see below for specific methods). Based on previous research, we expect that bilingual children will display sensitivity to coarticulation, just like their monolingual peers. However, no strong predictions can be made as to whether bilinguals' sensitivity will be lesser, equal to, or greater than that of monolinguals. On the one hand, some studies have documented that monolinguals and bilinguals show similar processing abilities (e.g. Byers-Heinlein, Fennell, \& Werker, 2013; Legacy, Zesinger, Friend, \& Poulin-Dubois, 2016), which would yield to similar patterns of sensitivity to coarticulation (i.e., equal disruption in word processing when mismatching cues are present) in monolinguals and bilinguals. On the other hand, some research has demonstrated a bilingual advantage in processing (for a review, see Bialystok, Craik, \& Luk, 2012) or that bilinguals lag behind their monolingual peers (Pelham \& Abrams, 2014). If these hypotheses are true, given the fact that both languages' systems influence each other (Brasileiro Reis Pereira, 2009; Fabiano \& Goldstein, 1995; Paradis, 2001), one might predict that English-French bilinguals' sensitivity to vowel nasalization will be different from that in monolingual English listeners. For example, since English-French bilingual children have to maintain a phonological contrast between nonnasalized and nasalized vowels in their (French) lexicon, one might expect their phonological system to treat coarticulatory vowel nasalization in English differently, perhaps with greater sensitivity to coarticulation. This prediction would be supported by the fact that bilingual listeners are exposed to more variability for this phonetic cue (Byers-Heinlein \& Fennell, 2014), and that this kind of variability may motivate maintaining fine-grained perceptual abilities for vowel nasalization in English-French bilingual children. 
The second goal of the current study is to examine if four- to six-year-old children are able to resolve coarticulatory mismatches within words, compared to the younger group from Zamuner et al. (2016). We are interested in this question because younger children (two- and three-year-olds) could not yet overcome the coarticulation mismatch in Zamuner et al.'s (2016) previous investigation. Since Huang and Snedeker (2011) found evidence that five-year-old children show sustained interference from competitors during word discrimination, we do not expect our group of four to six years old participants to resolve the phonetic mismatch as efficiently as adults. However, we predict that they will be more adult-like in their resolution of competitor interference than Zamuner et al.'s (2016) toddlers, given their older age.

\section{Methods}

\section{Participants}

The group of younger monolinguals were 19 children, aged 2;1 to 3;10, who completed the study published in Zamuner et al. (2016), and for whom the data was reanalyzed below in order to provide a comparison with the older monolingual group. ${ }^{2}$ The other children, aged

${ }^{2}$ We conducted a post-hoc power analysis using $G *$ Power 3.1.9.3 (Faul, Erdfelder, Lang, $\&$ Buchnier, 2007) to determine the achieved power of the Zamuner et al. (2016) study. We expected a large effect size $\left(f^{2}=0.35\right)$ based on the observation of the data, and an $a$ error probability (i.e. $p$-value) of 0.05 . Zamuner et al. (2016) tested the influence of one predictor (CROSS-SPLICING), which is one of the required arguments in G*Power. Since G*Power does not provide a way to perform power analyses for generalized additive mixed-effects models (GAMMs; see below), which is the statistical method that we are using in the current paper, the closest statistical test available in the software is Linear multiple regression: Fixed model, $R 2$ increase. We used this statistical test as an estimation of power for the current study. Note that the results of the power analysis are a general indication of achieved power, but we expect GAMMs to be robust against Type II errors even with a relatively small sample size. We found that the post-hoc Power (1- $\beta$ error probability) was 0.681 given a sample size of $N=19$. The results of the current power analysis should thus be interpreted with care, as the GAMM method is well suited to the eye tracking measures used here. 
between 4;0 and 6;11 years, completed the same experiment $(N=119)$. We focused on this age range to determine if children older than 3;0 years could resolve phonetic ambiguity created by mismatching phonetic cues. Children were tested in a sound-attenuated room on a university campus or museum-based lab. Twenty bilinguals (ten girls, ten boys; age range: 4;3 to 6;5 years; $M=5 ; 4$ years; $S D=8.1$ months) and twenty age-matched monolinguals (seven girls, thirteen boys; age range: $4 ; 3$ to $6 ; 5$ years; $M=5 ; 4$ years; $S D=8.2$ months) are included in the current analysis. ${ }^{3}$ Note that the majority of the data collection was conducted in a museum-based lab, which has the objective of involving the community in developmental research through research participation and knowledge translation to the families. In this context, parents are welcome to walk into the reception area of the museum-based lab and are offered to participate in the research with their child. Consequently, given the inclusive mandate of the testing setting, we did not restrict our recruitment criteria to only monolinguals and bilinguals, but rather provided an opportunity to the children to participate in a research activity. However, as we were interested in researching sensitivity to coarticulation and coarticulatory-mismatch solving abilities in monolinguals and bilinguals, our strategy was to select two groups of age-matched monolinguals and bilinguals. Note that all children from the large testing sample that fitted the inclusion criteria below were included in the analyses.

The final group of children included in the analyses were either English monolingual or English-French bilinguals who had not been diagnosed with a speech or hearing delay as

${ }^{3}$ We also conducted a post-hoc power analysis for the whole sample, which comprises $N=59$ children (19 children from Zamuner et al. (2016), 20 older monolinguals, and 20 older bilinguals). We investigated the impact of two predictors (AGE and LANGUAGE BACKGROUND), and thus achieved a power of 0.983 , expecting a large effect size. When expecting a medium effect size $\left(f^{2}=0.15\right)$, we achieved a power of 0.739 . We consider these values more than sufficient to pursue analyses using the current sample size. 
determined by parental questionnaire. Our criteria for determining bilingualism in children were established through parental report and are as follows: children had to be considered Englishdominant (i.e., $50 \%$ or more exposure to English in the family, to ensure that the children would know all of the used words in the experiment), had to be exposed to L2 French $\geq 30 \%$ of the time for two consecutive years (across contexts such as home, daycare/school, with extended family), had to be exposed to French as an L2 from the first year of life, and had to be exposed to L2 French at least $30 \%$ of the time through overall development. No participants spoke an L2 other than French. Due to the absence of wide-spread norms for establishing bilingualism status in L2 research, we required bilingual participants to be exposed to L2 French for more than a quarter of their linguistic interactions, therefore the $30 \%$ cut-off point. Bilingual children's average exposure to French across development was $45.1 \%, S D=7.8 \%$. Monolingual children had been exposed to French less than $30 \%$ overall and had been exposed to French for less than two consecutive years. Monolingual children's average exposure to French across development was $6.1 \%, S D=6.3 \%$. Note that in the Canadian education system, children can be exposed to French as an L2 relatively early, at four or five years old, which means that all children in our sample were likely exposed to French to some extent. Other children who were tested did not fit our bilingualism criteria or were not age-matched $(N=26)$ or contributed only one trial in one of the experimental conditions $(N=37)$. Note that these latter 37 children fixated to target images in filler trials, but did not meet our criterion of looking to at least two trials in both the same-splice and cross-splice conditions. There were 16 participants excluded based on a failure to calibrate or other technical problems $(N=14)$, fussing $(N=1)$, or parental interference $(N=1)$. 


\section{Stimuli}

Stimuli were six pairs of imageable English nouns (see Table 1). Each pair started with the same consonant and vowel, followed by either an oral consonant (e.g. boat [bout]) or a nasal consonant (e.g. bone [bõ̃un]), and both had the same place of articulation. As in Zamuner et al., (2016), three additional experimental pairs (duck-dumptruck, leg-lemon, and egg-M) were excluded from the analyses because of multiple coarticulation cues: nasalization and place of articulation. There were nine filler pairs (boots-carrot, star-keys, monkey-camel, frog-fish, dog-elephant, turtle-sandwich, chicken-kangaroo, doll-clock, and flower-sun). The stimuli were recorded by a female native speaker of Canadian English and normalized for amplitude at $70 \mathrm{~dB}$. A trained phonetician spliced the stimuli by keeping the initial and final consonants of an oral word token (e.g. [bout] $]_{1}$ ) and replacing the original vowel with one from another token of the same word (e.g. [bout $]_{2}$ ) or a nasal token (e.g. [bõ̃̃n] $)$, considering zero crossings to avoid acoustic artifacts like clicks or noises in the final signal. This yielded two SPLICING conditions: one with matching phonetic cues (same-splice, e.g. [b $\left.\mathrm{b}_{10 \mathrm{~J}_{2}} \mathrm{t}_{1}\right]$ ), and one with mismatching phonetic cues (cross-splice, e.g. [ $b_{1}$ õ $\left.\left._{N} t_{1}\right]\right)$. In Table 1, the two rightmost columns indicate the vowel onset timing within the target word. 
Table 1. List of the target-competitor pairs and durational details about the auditory stimuli.

\begin{tabular}{|c|c|c|c|c|c|c|}
\hline $\begin{array}{l}\text { Target } \\
\text { word }\end{array}$ & IPA & $\begin{array}{l}\text { Competitor } \\
\text { word }\end{array}$ & IPA & $\begin{array}{l}\text { CROSS-SPLICE } \\
\text { IPA }\end{array}$ & $\begin{array}{l}\text { V onset } \\
\text { SAME-SPLICE } \\
\text { in } \mathrm{ms}\end{array}$ & $\begin{array}{l}\mathrm{V} \text { onset } \\
\text { CROSS-SPLICE } \\
\text { in } \mathrm{ms}\end{array}$ \\
\hline boat & [bout] & bone & [bõõn] & [bõỡt] & 23 & 23 \\
\hline bug & {$[\mathrm{b} \wedge \mathrm{g}]$} & bunk(bed) & [b̃̃̄k] & {$[\mathrm{b} \tilde{\Lambda} \mathrm{g}]$} & 18 & 15 \\
\hline castle & [kæsł] & candy & [kãndi] & [k̃̃sł] & 198 & 148 \\
\hline cloud & [klavd] & clown & [klãõn] & [klãõd] & 238 & 250 \\
\hline hat & [hæt] & hand & [hæ̃nd] & [hr̃t] & 175 & 275 \\
\hline \multirow[t]{2}{*}{ kick } & [kık] & king & [kĩy] & [kĩk] & 140 & 206 \\
\hline & & & & Averages: & 132 & 153 \\
\hline
\end{tabular}

The images used in the experiment were the same size, and animacy was also controlled for within pairs (e.g. adding eyes to the cloud image which was paired with the image of a clown) in order to minimize preference effects in children. Potential frequency effects could not be controlled for due to the limited number of familiar and picturable $\mathrm{C}(\mathrm{C}) \mathrm{VC}-\mathrm{C}(\mathrm{C}) \mathrm{VN}$ English minimal pairs. We also could not include word frequency as a covariate in our analyses given the low number of items in our procedure, although this question could be the object of further investigations in the future.

\section{Design and procedure}

Children were tested by themselves or on their parent's lap. Eye gaze data was collected on an Eyelink1000 eye tracker in monocular remote mode, measuring movements of the right eye. The experimenter proceeded through a three-point calibration before the familiarization phase. During the familiarization, children saw each test and filler image and heard the corresponding unspliced label. During the experimental phase, children saw a central fixation 
point to ensure that they looked at the center of the screen at the beginning of the trial, then two images appeared on the screen. Experimental and filler images always appeared in the same pairs. Images were displayed for $1500 \mathrm{~ms}$, and then an audio clip with the phrase "Look at the [target]" played. The images remained on the screen for four seconds after the onset of the sound file; each trial lasted approximately six seconds. The entire experiment took approximately five minutes to complete, with a total 18 trials. The splicing condition in which each item was presented was counterbalanced across participants (e.g. half of the children heard boat in the SAME-SPLICE condition, and half in the CROSS-SPLICE condition).

\section{Results}

\section{Analysis procedure}

Eye movement data (right eye only) was extracted using DataViewer 2.16 in 50-ms time bins. Proportions of fixations to the target images within the time bins were calculated as:

$$
\% \text { fixations }=\frac{\text { duration of fixations to target }}{\text { duration of fixations to competitor }+ \text { duration of fixation to target }}
$$

The data were statistically analyzed using generalized additive mixed models (GAMMs; Wood, 2017), which can account for nonlinear trends through time, as found in eye tracking data.

GAMMs can also include (linear or nonlinear) random effects, and account for autocorrelation in the time-dependent data (i.e. one data point in time is necessarily correlated to the preceding data point, which can yield to an overconfidence of model estimates; Baayen, van Rij, de Cat, \& Wood, 2018; Porretta, Kyröläinen, van Rij, \& Järvikivi, 2018). Furthermore, GAMMs do not assume normal distribution of the data, which makes them appropriate for eye fixation data. We will present two models in the current paper: first, a GAMM for the fixations to the target (e.g. the boat image) in the CROSS-SPLICE splicing condition only to assess sensitivity to English nasal 
coarticulation in monolinguals and bilinguals as well as competitor inhibition patterns, and a second GAMM on the fixations to the target image in the filler trials to assess group differences between mono- and bilinguals in unspliced words.

The dependent variable of the GAMMs was the empirical-logit-transformed fixations (Barr, 2008) to the target. Empirical logits are an approximation of the log odds of looking to one image (e.g. the target) compared to the other image (e.g. the competitor), calculated as:

$$
\operatorname{elog}=\log \left(\frac{y+0.5}{N-y+0.5}\right)
$$

where $y$ corresponds to the number of samples during which the target was fixated, and $N$ corresponds to the total number of samples within the time bin (i.e. eye tracker sampling at 500 $\mathrm{Hz}$, thus 25 samples per $50-\mathrm{ms}$ time bin).

The independent factors of interest for the GAMMs were the TIME window of analysis (between $300 \mathrm{~ms}$ and $2000 \mathrm{~ms}$ for experimental trials, and between $300 \mathrm{~ms}$ and $1000 \mathrm{~ms}$ for filler trials, see below) and language BACKGROUND (young monolingual, old monolingual or old bilingual). We chose a shorter window of analysis for the filler trials since these were not spliced, were unambiguous, and there was no expected effect of phonological competition (e.g., the item star was presented next to the item keys). The peak in average fixations to the target in the filler trials occurred at approximately $750 \mathrm{~ms}$ for all three groups.

For the GAMM on experimental trials, we modeled empirical-logit-transformed fixations in the CROSS-SPLICE condition in order to assess sensitivity to phonetic mismatch. The time window of interest was chosen for analysis of experimental trials between $300 \mathrm{~ms}$ after word onset to account for eye movement programming delay (Buckler \& Fikkert, 2016; Zamuner et al., 2016) until $2000 \mathrm{~ms}$ after word onset, a time at which it is likely that children will continue to look at the images based on the prompt. Similarly to other GAMM analyses (Porretta et al., 
2016; 2018), random effects corresponded to a combination of participant and trial (i.e. EVENT), allowing each trial (for each participant) to have its own intercept in the model. An AR-1 autocorrelation value of 0.868 was empirically determined based on the data and included in the experimental GAMM formula, and a value of 0.706 for the filler items GAMM. Autocorrelation values correspond to the average correlation of a given data point with the preceding one in the time series. We present below a difference curve (fixations to the target by young monolinguals minus fixations by old monolinguals), generated from the GAMM, between younger monolinguals and older monolinguals to assess the differences in fixations to the target in the cross-splice condition, and thus examine if one or the other group was more sensitive to phonetic mismatches (i.e., sensitivity to coarticulation). We also present a difference curve between older bilinguals and monolinguals to assess the group differences concerning sensitivity to nasal coarticulation.

\section{Analysis of raw proportions of fixations, experimental trials}

In this analysis, we were interested in the effect of LANGUAGE BACKGROUND (bilingual or monolingual) and participant AGE (young monolinguals and old monolinguals) on sensitivity to nasal coarticulation. Eye tracking results in Figure 1 show the general effects of SPLICING condition on fixations to the target image. Higher values on the y-axis suggest that children tended to fixate the target image more. In all groups, participants looked more to targets in the SAME-SPLICE condition (grey lines) compared to the CROSS-SPLICE condition (blue lines). Focusing on the SAME-SPLICE condition (grey lines), there does not seem to be a difference between monolinguals and bilinguals, as demonstrated by similar shapes and overlapping error bars throughout the analysis window. However, young monolinguals fixated to the target slightly 
less than older monolinguals between $500 \mathrm{~ms}$ and $1000 \mathrm{~ms}$ within the trial, although the error bars seem to overlap with older children. This suggests relatively similar processing abilities for all children for SAME-SPLICE words.

In the CROSS-SPLICE condition (blue lines in Figure 1), bilinguals (triangles) maintained similar proportions of fixations to the target as older monolinguals, but young monolinguals (empty squares) fixated more to the target (e.g., boat) than both the older groups. Note that in our procedure, proportions of fixations were calculated based on fixations to the images only, which then suggests that young monolinguals shifted their gaze between the target (e.g., boat) and (nasal) competitor (e.g. bone) more than the other groups. This suggests that the younger group was disrupted by the phonetic mismatch, but that they also fixated less to the competitor image, which suggests less sensitivity to coarticulatory nasalization. In other words, young monolinguals did not inhibit the target (e.g., boat) as much as the older groups when hearing phonetic cues that corresponded to the nasal competitor (e.g., bone), thus that they might not consider coarticulation as much when processing words. 


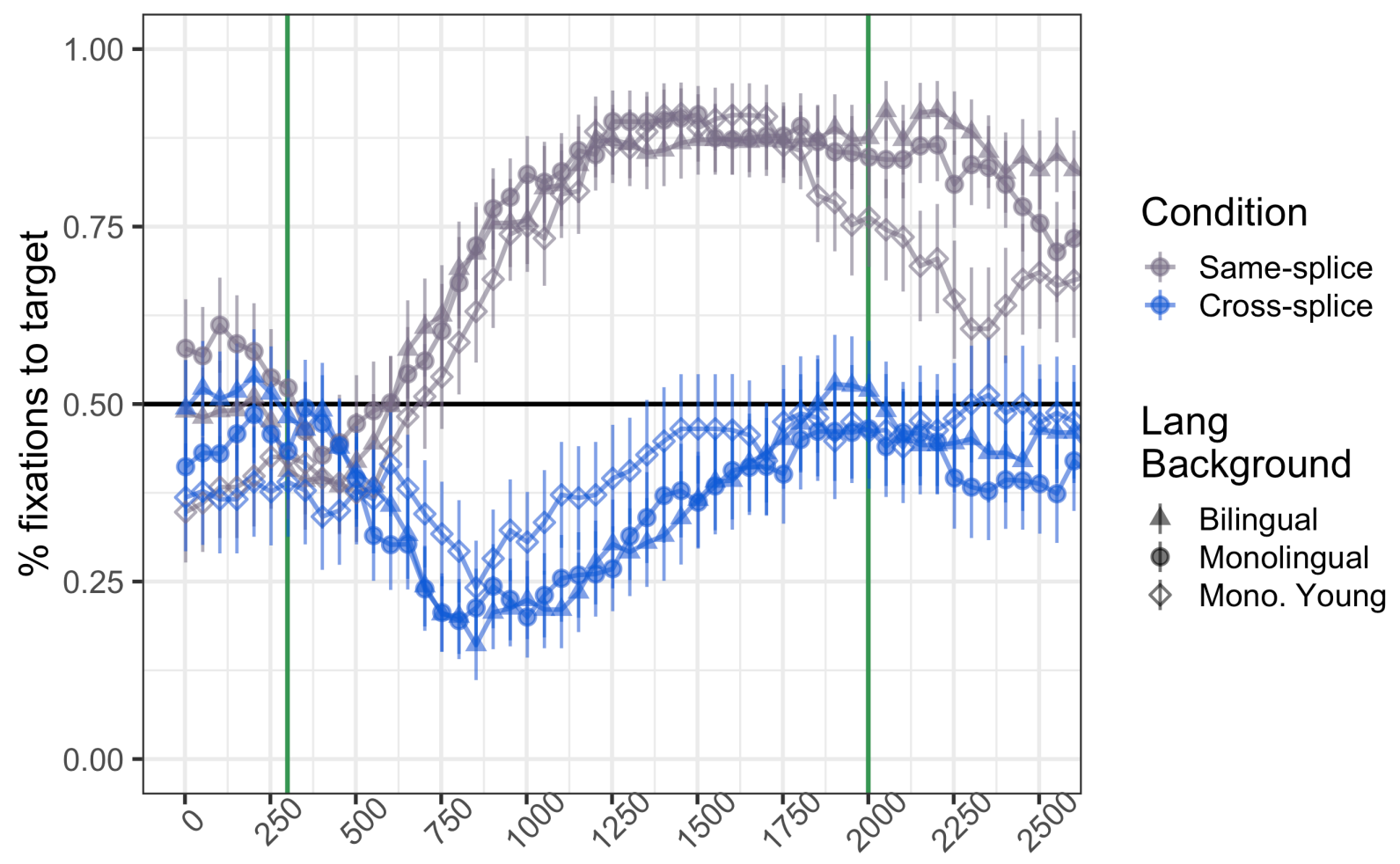

Time (ms) since word onset

Figure 1. Overall fixation patterns to the target by SPLICING condition and participant LANGUAGE BACKGROUND. Higher proportions of fixations on the y-axis correspond to more fixations to the target (e.g., boat) and lower proportions of fixations on the y-axis correspond to more fixations to the competitor (e.g., bone).

This finding is also supported by the statistical analysis presented in the difference curves in Figure 2 (also see Table A1 in Appendix). For illustration purposes, this figure presents difference curves in fixations to the target (e.g., blue empty-squares curve minus blue circles curve in Figure 1, and blue triangle curve minus blue circles curve in Figure 1) between young monolinguals and older monolinguals (Figure 2A), as well as between older bilinguals and older monolinguals (Figure 2B) within the TIME window (x-axis) on separate panels. These curves were computed with the plot_diff function of the itsadug package (van Rij, Wieling, Baayen, \& van Rijn, 2017). This function plots difference curves in predicted (mean and confidence 
intervals) data by the model. Portions of the difference curves that are significantly above or below 0 represent a significant difference between the two groups for a given time interval, and are noted with red-shaded intervals below. Y-values below 0 represent more fixations to the competitor by young monolinguals or bilinguals than old monolinguals, and y-values above 0 represent more fixations to the target image.

We were thus able to establish that young monolinguals fixated significantly more to the target in cross-spliced trials between $950 \mathrm{~ms}$ and $1385 \mathrm{~ms}$ when compared to older monolinguals (deviance explained of 39.7\%). This supports our observation that young monolinguals shift their gaze in the coarticulatory mismatch condition more than older monolinguals, thus that they might not be as sensitive to coarticulation than the latter group. Furthermore, towards the end of the trials, no differences in the raw data or statistical analysis emerged between younger and older monolinguals, suggesting that the older group did not resolve the phonetic mismatch better than the younger group.

The lack of apparent difference between older bilinguals and older monolinguals in the raw data (Figure 1) suggests that bilingual listeners were equally sensitive to nasal coarticulation than monolingual children overall: both groups were sensitive to coarticulation (i.e. see dip in blue curve for both groups in the time window of analysis in Figure 1). This is also borne out by the statistical analysis of cross-splice items, where no difference emerged when computing the difference curve in fixations to the target between bilinguals and monolinguals (Figure 2B). Although we are aware that it is difficult to formulate strong conclusions from null results, the overwhelming similarity of the fixation curves between older monolinguals and bilinguals in the cross-splice condition (Figure 1) points in the direction of similar sensitivity to nasal coarticulation in both groups. It is possible that using a different type of measure, age group or 
coarticulation contrast, one may see differences in processing between monolinguals and bilinguals. However, for the contrast tested in this study, we observed no statistical difference between the groups of monolinguals and bilinguals.

A

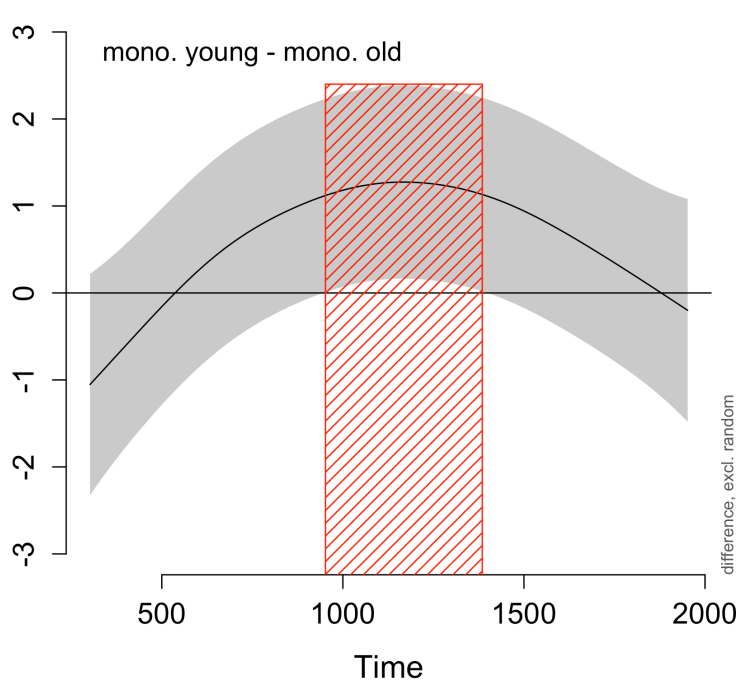

B

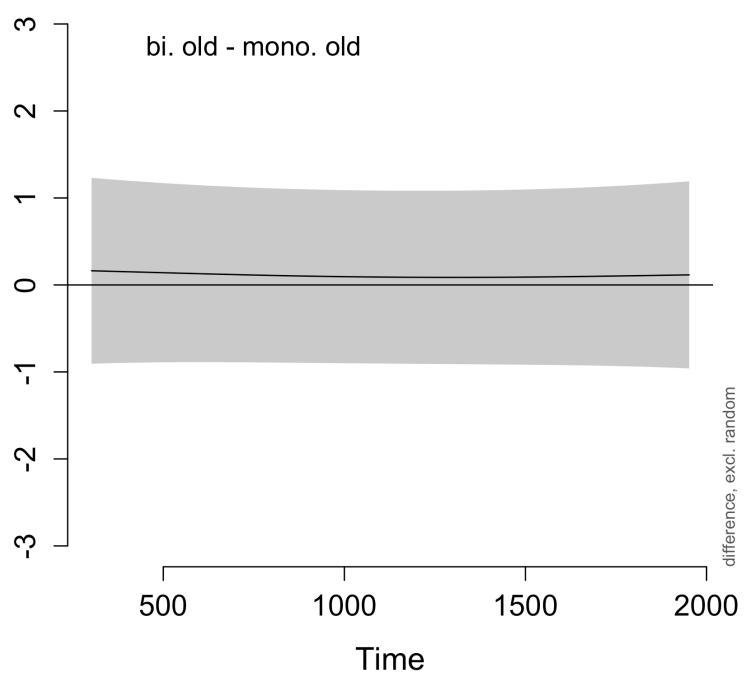

Figure 2. Difference curves (experimental trials) as predicted by the GAMM analysis for young monolinguals against old monolinguals (A) and old bilinguals against old monolinguals (B) in the cross-splice condition only. (Red) shaded area corresponds to the interval in which the difference is significant. Grey bands around the average curve corresponds to $95 \%$ confidence intervals.

\section{Analysis of filler trials}

This analysis compared all groups' fixations to targets on the filler trials (Figure 3) in order to assess the potential differences across groups when processing regular speech. In Figure 4, we show difference curves between young monolinguals and older bilinguals (A) as well as between older bilinguals and older monolinguals (B). Visualization of the GAMM results (see Table A2 in Appendix for the numeric output of the model; deviance explained of 56.2\%) in Figure 4 shows that young monolinguals fixated significantly less to the target for the entire duration of the trials (Figure 4A). However, there was no significant difference between 
monolingual and bilingual children in filler trials (Figure 4B). This means that, on the one hand, younger monolinguals were less efficient than older monolinguals at fixating to the target, but that (older) monolingual and bilingual participants process English filler words similarly. While it would be informative to have independent measures of children's language skills using standardized tests, this analysis of filler trials suggests that there are no differences in processing abilities for non-cross-spliced items in age-matched monolinguals and bilinguals, in addition to less efficient general processing in younger monolingual children compared to older children.

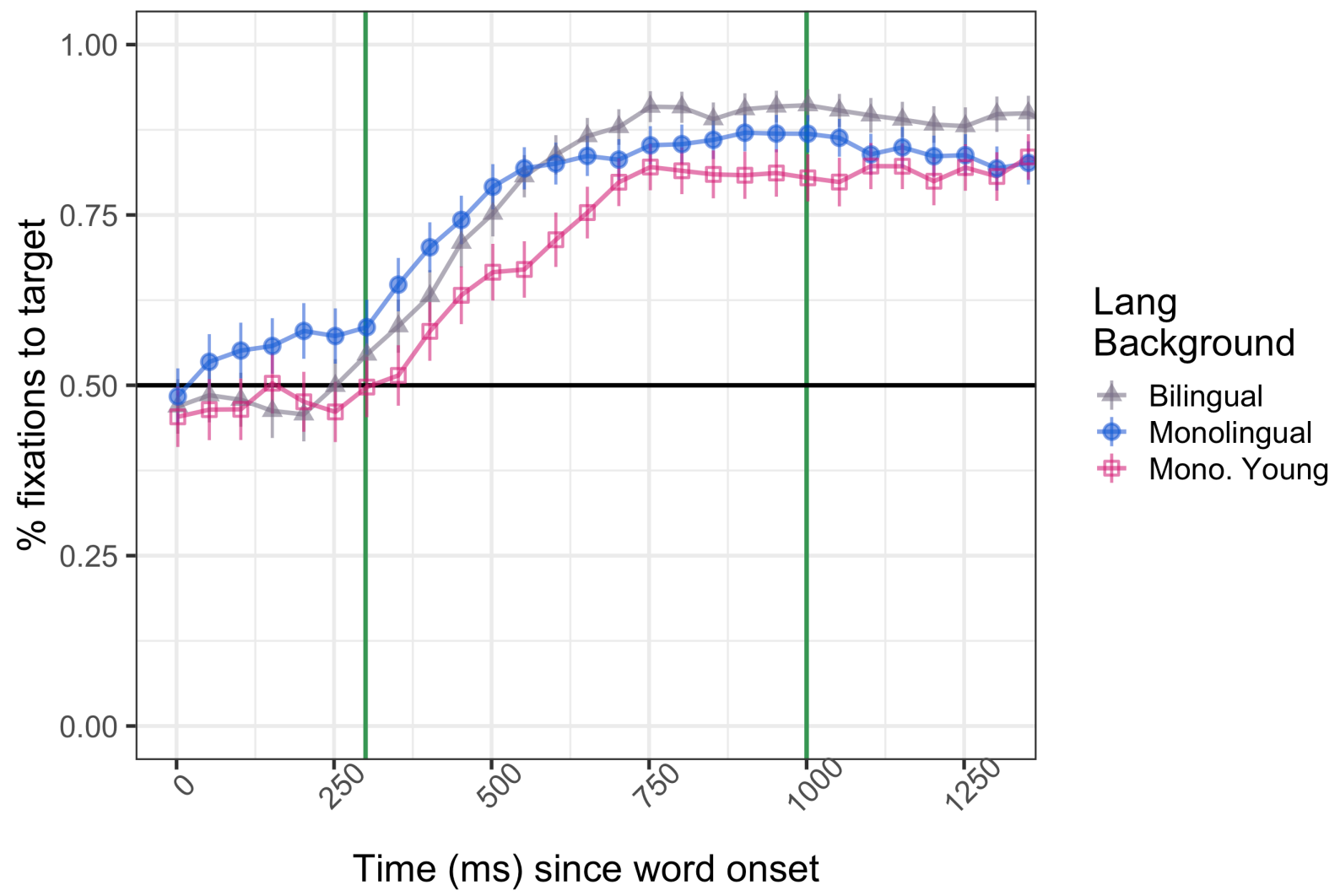

Figure 3. Overall fixation patterns to the target for filler trials by participant LANGUAGE BACKGROUND and AGE. The green bars/lines represent the window of analysis. 
A

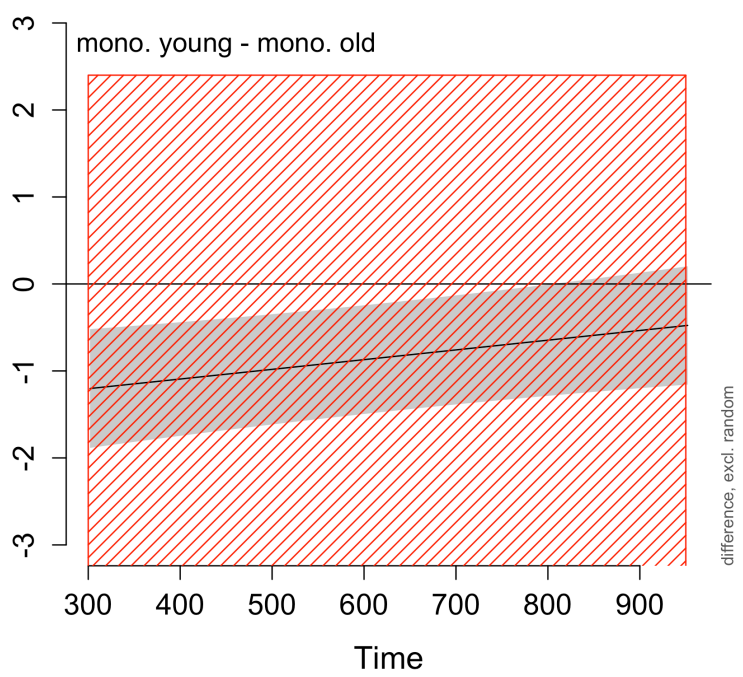

B

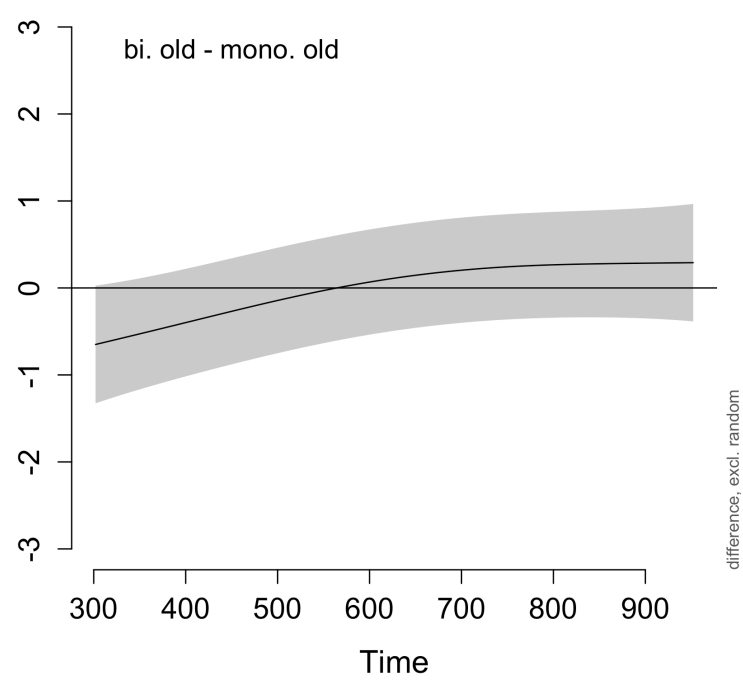

Figure 4. Difference curves (filler trials) as predicted by the GAMM analysis for young monolinguals against old monolinguals (A) and old bilinguals against old monolinguals (B). (Red) shaded area corresponds to the interval in which the difference is significant. Grey bands around the average curve corresponds to $95 \%$ confidence intervals.

\section{Discussion}

Bilingual spoken word recognition is made more complex because two languages exist in a listener's mind. While research has found that monolingual adults and toddlers are able to use English vowel nasalization during spoken word recognition (Beddor et al., 2013; Zamuner et al., 2016), little research has focused on the development of these abilities over time, and on how bilingual children process phonetic details during spoken word recognition. Thus, we investigated the development of English monolingual children's sensitivity to English coarticulatory vowel nasalization. We also examined how English-French bilingual children process English coarticulatory vowel nasalization.

First, we compared data from a group of younger monolingual children (aged 2 to 3 years) to a group of older monolingual children (aged 4 to 6 years). The statistical analysis shows that younger monolingual children tended to fixate slower and less to the target in the filler trials, 
which can be explained by a less mature word processing system. In the cross-splice condition, listeners were presented with targets that contained a mismatched nasalized vowel. This led all groups to fixate more to the competitor (bone) and less to the target (boat) for a portion of the trial. However, fixations to the target in the cross-splice condition were significantly higher for younger monolinguals than older monolinguals (i.e., closer to $50 \%$ proportions of fixations than older monolinguals, since both groups had fixations well below 50\% in this splicing condition). Thus, our data suggest that the older monolinguals were more sensitive to coarticulation (i.e., young monolinguals were not capable of inhibiting the non-nasalized target as much as old monolinguals), and the activation of the target was more disrupted by the mismatch (since at that point within the trial, the competitor is hypothesized to be activated). Consequently, one could argue that the older monolingual children were better at resolving the phonetic mismatch because they recovered from a larger disruption. However, looking at the amount of looking to the target in the cross-splice condition, both the younger monolinguals and older bilinguals peak at $50 \%$ looking to the target. Thus, fixation data indicate that even older monolingual children cannot resolve the phonetic mismatch (fixations hover around chance in the CROSS-SPLICE condition, $2000 \mathrm{~ms}$ after word onset), similarly to the younger toddler participants. This corresponds to the Huang and Snedeker (2011) explanation that children have sustained competitor interference, and it is not until children are older that they have more adult-like processing patterns (see also Rigler et al., 2015).

The second goal was to compare the processing of coarticulation cues that vary across languages in bilinguals and compare those results with a group of monolinguals. To do this, we examine English vowel nasalization in a group of English monolinguals and a group of EnglishFrench bilinguals. English and French are ideal languages to investigate this question, since 
French uses vowel nasalization as a phonological distinction (Cohn, 1990), while English contains vowel nasalization as merely a coarticulatory property (Beddor, 2009). We initially predicted that bilingual children would be sensitive to nasal coarticulation in English, but made no strong prediction on the potential differences between monolingual and bilingual children's processing of nasal coarticulation. Past research has argued that monolinguals and bilinguals process language similarly (Byers-Heinlein et al., 2013), in which case no difference is expected between our groups. However, others have suggested a bilingual advantage (Bialystok et al., 2012) or disadvantage (Pelham \& Abrams, 2014), in which cases we expect to find differences across the groups concerning sensitivity to nasal coarticulation. We found that monolingual and bilingual children displayed similar sensitivity to vowel nasalization (Legacy et al., 2018), as shown by similar patterns of fixations to the target images, across the time course, and in both the same-splice and cross-splice conditions. This is in line with some research showing that monolinguals and bilinguals process certain aspects of language similarly. Given that the children in our study were relatively-balanced bilinguals and exposed to both English and French from a young age, perhaps it is not surprising that the bilinguals were not different from the monolinguals in processing the coarticulation cues. Moreover, while French has a phonological contrast between oral and nasal vowels and English has pervasive nasal coarticulation between nasal consonants and oral vowels, this also means that English monolingual children are being exposed to cues of nasalization in their linguistic environment. Perhaps this is enough for English monolinguals to develop similar sensitivity to nasal coarticulation as English-French bilinguals, even though the way the cues are used in the different languages varies. It is possible that if one were to test a cue that occurs in only one of the two languages, there would be evidence of differences between bilinguals and monolinguals. 
In summary, we find that children's sensitivity to coarticulation cues grows between the ages of two to six years; however, older children continue to have sustained competitor interference. We also found that bilingual children' sensitivity to coarticulatory information in their L1 patterns similarly to that of monolinguals', even when the coarticulatory cue is contrastive in their L2. Our results are in line with previous studies showing equal sensitivity for bilinguals and monolinguals (Liu \& Kager, 2018).

There are a number of possible directions for future research. First, a parallel study in French with French monolingual and English-French bilingual children would answer whether there are any bi-directional effects in how bilingual and monolingual children process phonological and coarticulatory vowel nasalization differently from monolinguals. Second, one could examine a group of younger English-French bilinguals to establish whether they are similar to the English monolinguals. We predict that a similar group of younger bilinguals would perform like the younger monolinguals. This is because our older bilinguals were relatively balanced in their exposure to English and French - recall that the bilingual children's average exposure to French across development was $45.1 \%$. This leads to another avenue for future research, which would be to examine processing in bilinguals with different language experience, to see whether less proficient bilinguals would be more likely to draw on the phonemic inventory of their L1 to facilitate speech perception in their L2, and vice versa (Desmeules-Trudel \& Zamuner, under review). For example, to see whether children who were more dominant in French would show more sensitivity to English nasalization, as a cross-over transfer from French.

While the current findings raise a number of intriguing questions, our findings support the idea that phonological representations are rich and include phonetic details (Browman \& 
Goldstein, 1986; Pierrehumbert, 2002), such as coarticulation. This research also highlights that in some instances, bilinguals can show similar processing to their monolingual peers. The historically monolingual focus in language research belies the fact that a majority of the world's children are exposed to more than one language (Grosjean, 1982). It is therefore crucial to understand how speech perception, and linguistic skills more generally, develop in this, the majority population. 


\section{References}

Archangeli, D. (1988). Aspects of underspecification theory. Phonology, 5(2), 183-207. doi: $10.1017 / \mathrm{s} 0952675700002268$

Archibald, L. M. D., \& Joanisse, M. F. (2011). Electrophysiological responses to coarticulatory and word level miscues. Journal of Experimental Psychology: Human Perception and Performance, 37(4), 1275-1291. doi:10.1037/a0023506

Baayen, R. H., van Rij, J., de Cat, C., \& Wood, S. (2018). Autocorrelated Errors in Experimental Data in the Language Sciences: Some Solutions Offered by Generalized Additive Mixed Models. In D. Speelman, K. Heylen, \& D. Geeraerts (Eds.), Mixed-Effects Regression Models in Linguistics, (pp. 49-69). doi:10.1007/978-3-319-69830-4_4

Barcroft, J., \& Sommers, M. S. (2005). Effects of acoustic variability on second language vocabulary learning. Studies in Second Language Acquisition, 27(3), 387-414. doi: $10.1017 / \mathrm{s} 0272263105050175$

Barr, D. J. (2008). Analyzing "visual world" eyetracking data using multilevel logistic regression. Journal of Memory and Language, 59(4), 457-474. doi:10.1016/j.jml.2007.09.002

Beddor, P. S. (2009). A coarticulatory path to sound change. Language, 85(4), 785-821. doi:10.1353/lan.0.0165

Beddor, P. S., McGowan, K. B., Boland, J. E., Coetzee, A. W., \& Brasher, A. (2013). The time course of perception of coarticulation. The Journal of the Acoustical Society of America, 133(4), 2350-2366. doi:10.1121/1.4794366

Brasileiro Reis Pereira, I. (2009). The Effects of Bilingualism on Children's Perception of Speech Sounds. Utrecht, NL: LOT. 
Browman, C. P., \& Goldstein, L. M. (1986). Towards an articulatory phonology. Phonology, 3, 219-252. doi:10.1017/s0952675700000658

Buckler, H., \& Fikkert, P. (2016). Dutch and German 3-year-olds' representations of voicing alternations. Language and Speech, 59(2), 236-265. doi:10.1177/0023830915587038

Burns, T. C., Yoshida, K. A., Hill, K., \& Werker, W. F. (2007). The development of phonetic representation in bilingual and monolingual infants. Applied Psycholinguistics, 28(3), $455-$ 474. doi:10.1017/s0142716407070257

Bialystok, E., Craik, F. I. M., \& Luk, G. (2012) Bilingualism: Consequences for mind and brain. Trends in Cognitive Sciences, 16(4), 240-250. doi:10.1016/j.tics.2012.03.001

Byers-Heinlein, K. (2013). Parental language mixing: Its measurement and the relation of mixed input to young bilingual children's vocabulary size. Bilingualism: Language and Cognition, 16(1), 32-48. doi:10.1017/s1366728912000120

Byers-Heinlein, K., \& Fennell, C. T. (2014). Perceptual narrowing in the context of increased variation: Insights from bilingual infants. Developmental Psychobiology, 56(2), 274-291. doi:10.1002/dev.21167

Byers-Heinlein, K., Fennell, C. T., \& Werker, J. F. (2013). The development of associative word learning in monolingual and bilingual infants. Bilingualism: Language and Cognition, 16(1), 198-205. doi:10.1017/S1366728912000417

Cohn, A. C. (1990). Phonetic and phonological rules of nasalization (Unpublished doctoral dissertation). University of California Los Angeles, Los Angeles, CA.

Cross, A. M., \& Joanisse, M. F. (2018). Eyetracking of coarticulatory cue responses in children and adults. Language, Cognition and Neuroscience, 33(10), 1315-1324. doi: $10.1080 / 23273798.2018 .1484148$ 
Curtin, S., Byers-Heinlein, K., \& Werker, J. F. (2011). Bilingual beginnings as a lens for theory development: PRIMIR in focus. Journal of Phonetics, 39(4), 492-504. doi:10.1016/j.wocn.2010.12.002

Dahan, D., Magnuson, J. S., Tanenhaus, M. K., \& Hogan, E. M. (2001). Subcategorical mismatches and the time course of lexical access: Evidence for lexical competition. Language and Cognitive Processes, 16(5-6), 507-534. doi:10.1080/01690960143000074

Delattre, P. (1965). La nasalité vocalique en français et en anglais. The French Review, 39(1), 92-109.

Desmeules-Trudel, F., \& Brunelle, M. (2018). Phonotactic restrictions condition the realization of vowel nasality and nasal coarticulation: Duration and airflow measurements in Québécois French and Brazilian Portuguese. Journal of Phonetics, 69, 43-61. doi:10.1016/j.wocn.2018.05.001

Desmeules-Trudel, F., \& Zamuner, T. S. (2019). Gradient and categorical patterns of spokenword recognition and processing of phonetic details. Attention, Perception, \& Psychophysics. doi:10.3758/s13414-019-01693-9

Desmeules-Trudel, F., \& Zamuner, T. S. (under review). Spoken word recognition in a second language: The importance of phonetic details, assimilation, and external factors.

Fabiano, L., \& Goldstein, B. (2005). Phonological cross-linguistic effects in bilingual SpanishEnglish speaking children. Journal of Multilingual Communication Disorders, 3(1), 5663. doi:10.1080/14769670400027316

Faul, F., Erdfelder, E., Lang, G., \& Buchner, A. (2007). G*Power 3: A flexible statistical power analysis program for the social, behavioral, and biomedical science. Behavior Research Methods, 39(2), 171-191. doi:10.3758/bf03193146 
Flege, J. E. (2007). Language contact in bilingualism: Phonetic system interactions. Laboratory Phonology, 9, 353-382.

Fowler, C. A. (1980). Coarticulation and theories of extrinsic timing. Journal of Phonetics, 8, 113-133.

Fujimura, O. (1962). Analysis of nasal consonants. The Journal of the Acoustical Society of America, 34(12), 1865-1875. doi:10.1121/1.1909142

Gow, D. W. (2003). Feature parsing: Feature cue mapping in spoken word recognition. Perception \& Psychophysics, 65(4), 575-590. doi:10.3758/bf03194584

Grosjean, F. (1982). Life with two Languages: An Introduction to Bilingualism. Cambridge, MA: Harvard University Press.

Huang, Y. T., \& Snedeker, J. (2011). Cascading activation across levels of representation in children's lexical processing. Journal of Child Language, 38(3), 644-661. Doi: $10.1017 / \mathrm{s} 0305000910000206$

Johnson, E. K., \& Jusczyk, P. W. (2001). Word segmentation by 8-month-olds: When speech cues count more than statistics. Journal of Memory and Language, 44(4), 548-567. doi:10.1006/jmla.2000.2755

Keating, P. A. (1988). Underspecification in Phonetics. Phonology, 5(02), 275-292. doi:10.1017/s095267570000230x

Kuhl, P. K., Conboy, B. T., Coffey-Corina, S., Padden, D., Rivera-Gaxiola, M., \& Nelson, T. (2008). Phonetic learning as a pathway to language: new data and native language magnet theory expanded (NLM-e). Philosophical Transactions of the Royal Society B: Biological Sciences, 363(1493), 979-1000. doi:10.1098/rstb.2007.2154 
Kurowski, K. M., \& Blumstein, S. E. (1993). Acoustic properties for the perception of nasal consonants. In M. K. Huffman \& R. A. Krakow (Eds.), Nasals, Nasalization, and the Velum (pp. 197-222). London, UK: Academic Press.

Lahiri, A., \& Marslen-Wilson, W. (1991). The mental representation of lexical form: A phonological approach to the recognition lexicon. Cognition, 38, 245-294. doi:10.1016/0010-0277(91)90008-R

Legacy, J., Zesinger, P., Friend, M., \& Poulin-Dubois, D. (2018). Vocabulary size and speed of word recognition in very young French-English bilinguals: A longitudinal study. Bilingualism: Language and Cognition, 21(1), 137-149. doi:10.1017/S1366728916000833

Liu, L., \& Kager, R. (2018). Monolingual and bilingual infants' ability to use non-native tone for word learning deteriorates by the second year After birth. Frontiers in Psychology, 9. doi:10.3389/fpsyg.2018.00117

Macleod, A. A. N., \& Stoel-Gammon, C. (2009). The use of voice onset time by early bilinguals to distinguish homorganic stops in Canadian English and Canadian French. Applied Psycholinguistics, 30(1), 53-77. doi:10.1017/s0142716408090036

Maeda, S. (1993). Acoustics of vowel nasalization and articulatory shift in French nasal vowels. In M. K. Huffman \& R. A. Krakow (Eds.), Nasals, Nasalization, and the Velum (pp. 147167). London, UK: Academic Press.

Mahr, T., McMillan, B. T. M., Saffran, J. R., Ellis Weismer, S., \& Edwards, J. (2015). Anticipatory coarticulation facilitates word recognition in toddlers. Cognition, 142, 345350. doi:10.1016/j.cognition.2015.05.009 
McMurray, B., Clayards, M. A., Tanenhaus, M. K., \& Aslin, R. N. (2008). Tracking the time course of phonetic cue integration during spoken word recognition. Psychonomic Bulletin \& Review, 15(6), 1064-1071. doi:10.3758/pbr.15.6.1064

McMurray, B., Tanenhaus, M. K., \& Aslin, R. N. (2002). Gradient effects of within-category phonetic variation on lexical access. Cognition, 86(2), B33-B42. doi:10.1016/s00100277(02)00157-9

Paquette-Smith, M., Fecher, N., \& Johnson, E. K. (2016). Two-year-olds' sensitivity to subphonemic mismatch during online spoken word recognition. Attention, Perception, \& Psychophysics, 78(8), 2329-2340. doi:10.3758/s13414-016-1186-4

Paradis, J. (2001). Do bilingual two-year-olds have separate phonological systems? International Journal of Bilingualism, 5(1), 19-38. doi:10.1177/13670069010050010201

Pelham, S. D., \& Abrams, L. (2014). Cognitive advantages and disadvantages in early and late bilinguals. Journal of Experimental Psychology: Learning, Memory, and Cognition, 40(2), 313-325. doi:10.1037/a0035224

Pierrehumbert, J. B. (2002). Word-specific phonetics. In C. Gussenhoven \& N. Warner (Eds.), Laboratory Phonology 7 (pp. 101-139). Berlin: Mouton De Gruyter.

Porretta, V., Kyröläinen, A.-J., van Rij, J., \& Järvikivi, J. (2018). Visual World Paradigm data: From preprocessing to nonlinear time-course analysis. In I. Czarnowski, R. J. Howlett, \& L. C. Jain (Eds.), Intelligent Decision Technologies 2017, 268-277. doi:10.1007/978-3319-59424-8_25

Porretta, V., Tucker, B. V., \& Järvikivi, J. (2016). The influence of gradient foreign accentedness and listener experience on word recognition. Journal of Phonetics, 58, 1-21. doi:10.1016/j.wocn.2016.05.006 
Ramon-Casas, M., Fennell, C. T., \& Bosch, L. (2017). Minimal-pair word learning by bilingual toddlers: the Catalan /e/-/E/ contrast revisited. Bilingualism: Language and Cognition, 20(3), 649-656. doi:10.1017/s1366728916001115

Ramon-Casas, M., Swingley, D., Sebastián-Gallés, N., \& Bosch, L. (2009). Vowel categorization during word recognition in bilingual toddlers. Cognitive Psychology, 59(1), 96-121. doi:10.1016/j.cogpsych.2009.02.002

Rigler, H., Farris-Trimble, A., Greiner, L., Walker, J., Tomblin, J. B., \& McMurray, B. (2015). The slow developmental time course of real-time spoken word recognition. Developmental Psychology, 51(12), 1690-1703. doi:10.1037/dev0000044

Rost, G. C., \& McMurray, B. (2009). Speaker variability augments phonological processing in early word learning. Developmental Science, 12(2), 339-349. doi:10.1111/j.14677687.2008.00786.x

Salverda, A. P., Kleinschmidt, D., \& Tanenhaus, M. K. (2014). Immediate effects of anticipatory coarticulation in spoken-word recognition. Journal of Memory and Language, 71(1), 145163. doi:10.1016/j.jml.2013.11.002

Sekerina, I. A., \& Brooks, P. J. (2007). Eye movements during spoken word recognition in Russian children. Journal of Experimental Child Psychology, 98(1), 20-45. doi:10.1016/j.jecp.2007.04.005

Steriade, D. (1995). Underspecification and markedness. In J. Goldsmith (Ed.), The Handbook of Phonological Theory (pp. 114-175). Malden, MA: Wiley-Blackwell.

Sundara, M., Polka, L., \& Genesee, F. (2006). Language-experience facilitates discrimination of /d-/ in monolingual and bilingual acquisition of English. Cognition, 100(2), 369-388. doi:10.1016/j.cognition.2005.04.007 
Swingley, D., Pinto, J. P., \& Fernald, A. (1999). Continuous processing in word recognition at 24 months. Cognition, 71(2), 73-108. doi:10.1016/s0010-0277(99)00021-9

van Rij, J., Wieling, M., Baayen, R., \& van Rijn, H. (2017). itsdaug: Interpreting Time Series and Autocorrelated Data Using GAMMs. [R package]

Wood, S. N. (2017). Generalized Additive Models: An Introduction with R (2 $2^{\text {nd }}$ ed.). Boca Raton, FL: Chapman and Hall/CRC.

Zamuner, T. S., Moore, C., \& Desmeules-Trudel, F. (2016). Toddlers' sensitivity to within-word coarticulation during spoken word recognition: Developmental differences in lexical competition. Journal of Experimental Child Psychology, 152, 136-148.

doi:10.1016/j.jecp.2016.07.012 


\section{Appendix}

Table A1. Summary of the GAMM (experimental trials) output.

\begin{tabular}{llllll} 
Parametric coefficients & Estimate & Std. Error & $\mathrm{t}$-value & p-value & \\
\hline Intercept & -1.461 & 0.36 & -4.056 & $<0.001$ & $* * *$ \\
BACKGROUND[MONO.YOUNG] & 0.563 & 0.542 & 1.04 & 0.298 & \\
BACKGROUND[BI.OLD] & 0.109 & 0.505 & 0.216 & 0.829 & \\
\hline Smooth terms & edf & Ref.df & F-value & p-value & \\
\hline s(TIME) & 5.719 & 6.86 & 32.833 & $<0.001$ & $* * *$ \\
s(TIME):BACKGROUND[MONO.OLD] & 1.009 & 1.016 & 0.468 & 0.498 & \\
s(TIME):BACKGROUND[MONO.YOUNG] & 2.35 & 3.151 & 10.426 & $<0.001$ & $* * *$ \\
s(TIME):BACKGROUND[BI.OLD] & 1.149 & 1.278 & 0.288 & 0.569 & \\
RANDOM_EVENT & 147.167 & 156 & 17.743 & $<0.001$ & $* * *$ \\
\hline
\end{tabular}

Significance codes: ' 0 ' *** ‘ 0.001 '** ‘ 0.01 '* ‘ 0.05 '

Table A2. Summary of the GAMM (fillers) output.

\begin{tabular}{llllll} 
Parametric coefficients & Estimate & Std. Error & $\mathrm{t}$-value & $\mathrm{p}$-value & \\
\hline Intercept & 2.691 & 0.212 & 12.671 & $<0.001$ & $* * *$ \\
BACKGROUND[MONO.YOUNG] & -0.84 & 0.318 & -2.638 & $<0.01$ & $* *$ \\
BACKGROUND[BI.OLD] & -0.014 & 0.299 & -0.046 & 0.963 & \\
\hline Smooth terms & edf & Ref.df & F-value & p-value & \\
\hline s(TIME) & 3.772 & 4.66 & 63.478 & $<0.001$ & $* * *$ \\
s(TIME):BACKGROUND[MONO.OLD] & 1.001 & 1.002 & 6.61 & $<0.05$ & $*$ \\
s(TIME):BACKGROUND[MONO.YOUNG] & 0.011 & 0.021 & 0.097 & 0.964 & \\
s(TIME):BACKGROUND[BI.OLD] & 2.058 & 2.565 & 1.402 & 0.216 & \\
RANDOM_EVENT & 421.541 & 457 & 12.782 & $<0.001$ & $* * *$ \\
\hline
\end{tabular}

Significance codes: ' 0 ' *** ' 0.001 '** ‘ 0.01 ' * ‘ 0.05 ' 